\title{
Static Loading with Axial Channel for Hydrodynamic Journal Bearing Calculation Method
}

\author{
Hakan Adatepe \\ Department of Energy Systems Engineering, Faculty of Engineering, Giresun University, 28200, Giresun, Turkey
}

\begin{abstract}
In this study, the calculation method required to transport the load in axial channel lubricated hydrodynamic journal bearings is the yield. Distortion analyzes of existing (designed) bearings can also be carried out with the method presented here, the performance of the bearing can be investigated and used to investigate what can be done to improve the performance of the bearing. The method presented here can be used for two axial grooved bearings to the right and left of the load direction. Alternative oil distribution patterns can also be negotiated. The journal bearing is statically loaded. But in applications where loads and speed change are slow, the calculation method can be used here. This study mainly consists of two parts. In the first part, the operation of a hydrodynamic journal bearing is defined and a method is given for estimating the required dimensions of the bearing and detailed information is given for bearing design parameters. In the second part, a method for the analysis of a journal bearing is given and necessary information is given for the safe operation of the bearing.
\end{abstract}

Keywords: Axial Channel, Hydrodynamic Journal Bearing, calculation method

DOI: $10.7176 /$ JIEA/9-3-05

Publication date:May $31^{\text {st }} 2019$

\section{Giriş}

Bir hidrodinamik kaymalı yatağın çalışması özetle mil kama şeklinde bir boşluk içerisindeki viskoz bir yağlayıcı tarafından desteklenmesi şeklindedir. Mil yatak boşluğu içerisinde taşınan yükün etkisi altında eksantrik bir konum alır. Şekil 3.1 de görüldüğü gibi yük, yağ filminin karşıladığı basınçlar tarafından dengede olana kadar eksantrisite ayarlanır.

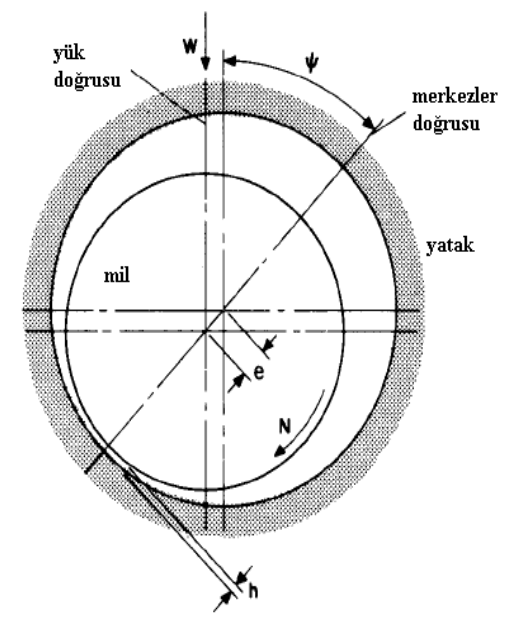

Şekil 1. Hidrodinamik radyal kaymalı yatak sistemi

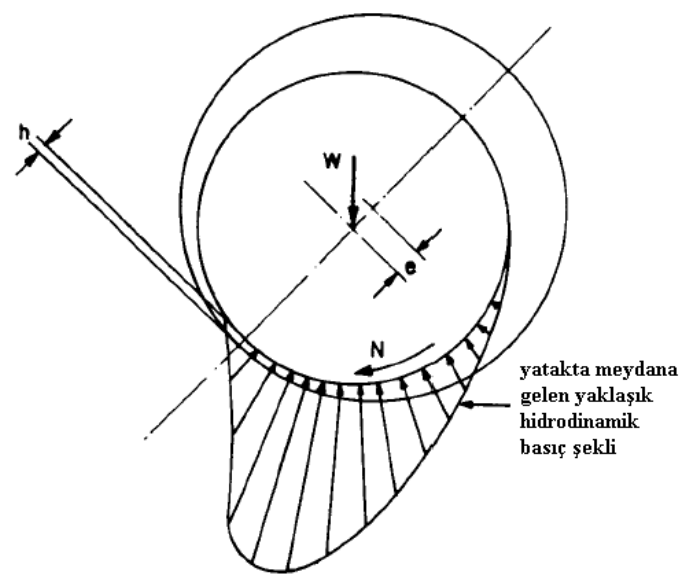

Şekil 2. Bir kaymalı yatakta basınç dağılımı 


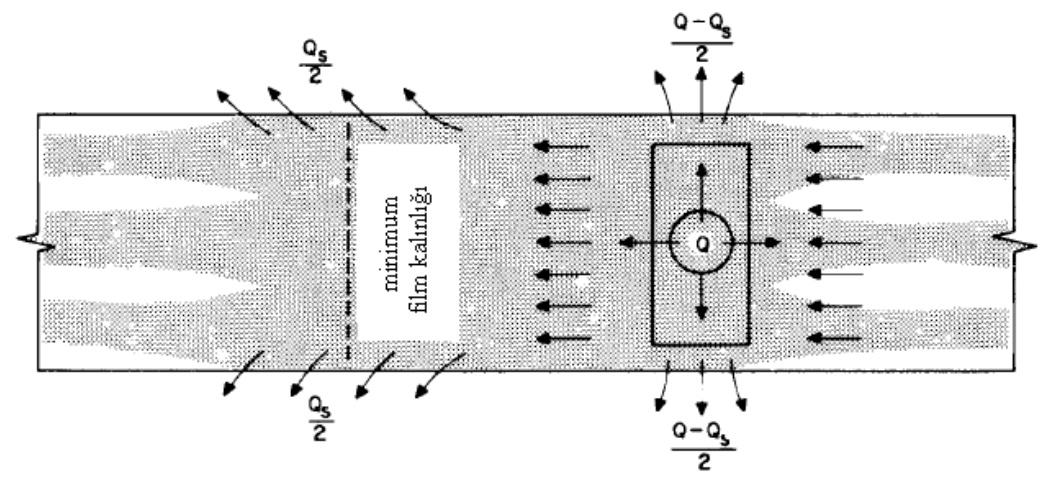

a. $Q>Q_{s}$ olduğunda idealleştirilmiş yağ akış

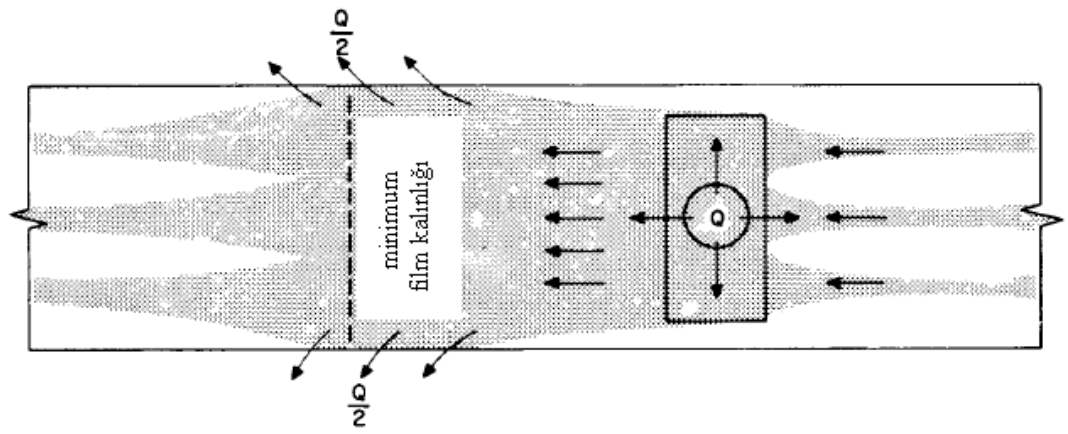

b. $Q<Q_{s}$ olduğunda

Şekil 3. İdealleştirilmiş yağ akış

Yağlanmış yataklar (kaymalı yataklar) genellikle beyaz maden olarak adlandırılan bir malzemeyle kaplanmıştır. Mil ise genellikle karbonlu çelikten imal edilmiştir. Yataklar genellikle kolayca monte edilmesi için çap boyunca ikiye ayrılmaktadır. Bu çalışmadaki yataklara yağ, yük doğrusuna $90^{\circ}$ tek eksenel kanal (Şekil 4 deki gibi) veya yük doğrultusunun sağında ve solunda $90^{\circ}$ olacak şekilde (Şekil 5 deki gibi) iki eksenel kanaldan verilir. Her iki yağlayıcı kanalları parçalı yataklar için uygundur.
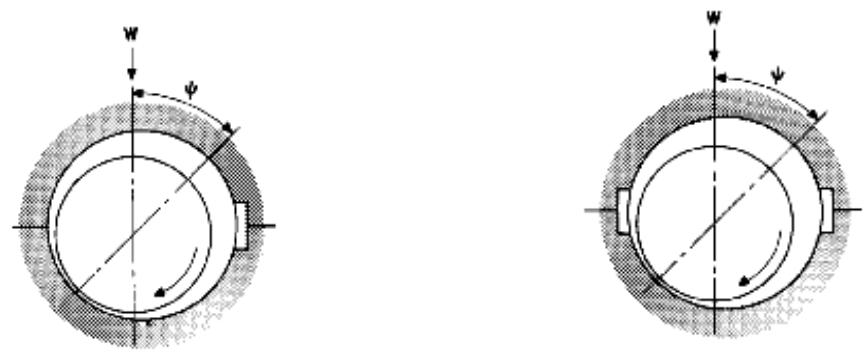

Şekil 4. Yük doğrultusuna dik tek eksenel (a), iki eksenel (b) kanallı yatak

İki eksenel kanallı yatak şekilde de görüldüğü gibi çapın her iki tarafında milin sağ veya sola dönüşü için uygundur.

\section{DIZAYN ICÇIN GEREKLİ PARAMETRELER} verebiliriz

Kaymalı yatakların analizi ve dizaynı için gerekli parametreleri tasarlamak için temel bilgileri şöylece

\section{Yük ve Hız}

Yük $W$, milin dönme frekansı (devir sayısı) $N$, sabit yük ve milin sabit devir sayısına döndüğü kabul 
edilir. Kısa sürede hızlanmalarda tolere olabilir belli devir sayısı not edilebilir. Bununla birlikte bazen dizaynsız (off design) yükler ve hızlar çok kötü çalışma şartlarında yükselmeye neden olur. Bu yüzden tüm potansiyel kritik şartlar altında yatakların çalışmasını araştırmak tavsiye edilir. Düşük hızlarda taşınan aşırı yüklerde film kalınlığı kritik olabilir. Aşırı yüklerde ve yüksek hızlarda çalışıyorken ise sıcaklık kritik olabilir. Başlangıç yükü de önemli bir faktördür.

\section{Çapsal Sınırlamalar}

Mil çapı d için genellikle mukavemet veya rijitlik değerleri önceden istenir. Yatak genişliği b için bir değer seçildiğinde b için bölüm 5'de verilen b/d oranları tavsiye edilir. Bazen kullanılacak b/d oranını daha uygun bir değere taşımak için mil çapında bir artışa gereksinim olabilir.

\section{Yağlayıcı}

Yağlayıcı bazen diğer yatak parametrelerin uygun tasarım için gerekli olmaktadır. Tasarımcı Şekil 5'de verilen şekle göre sistemde iş görecek ve kullanılacak mineral yağın seçimini yapar.

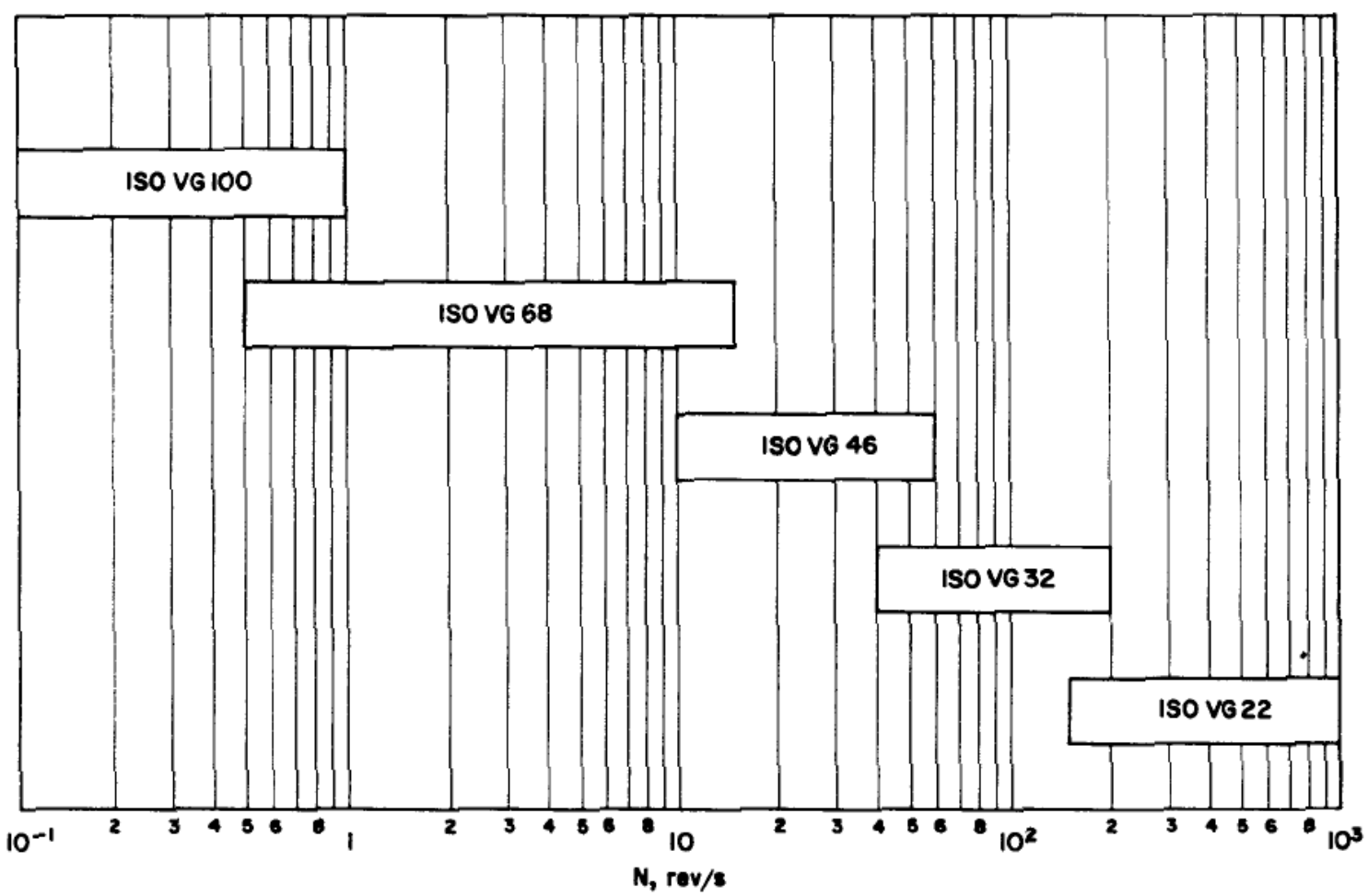

Şekil 5. Yağ seçimi için önerilen grafik

Yatağın performansını analiz etmek amacıyla yatağa gönderilen yağın sıcaklığı $T_{f}$ için bir kabul gereklidir. Çünkü bu değer sıcaklık artışının hesabında kullanılacaktır. Örnek olarak $T_{f}$ için bu değer yağlı yataklar için $40{ }^{\circ} \mathrm{C}$ veya $50{ }^{0} \mathrm{C}$ labilir. Genel durumlarda yağın besleme basıncı $p_{f} 0.05 \mathrm{MN} / \mathrm{m}^{2}$ ve 0.35 $M N / m^{2}$ arasına olmasi yeterli olacaktır.

\section{ILK YATAK DİZAYNI}

Bir yatak ilk kez dizayn edileceğinde genellikle yaygın kabuller kullanılarak yaklaşık bir dizaynla işe başlanır. 
(i) Son yatak boyutları ve performansı hesaplanmadan daha kapsamlı iterative dizayn işlemi için iyi bir başlangıç noktası sağlanmalıdır.

(ii) Emniyetli ideal sınırlamalardan daha düşük olup olmadığı yani bir yatak dizaynını gerçekleştirmek için belirlenen boşluk sınırlamasını karşılayacak şekilde olabilir.

Tasarımcılar genellikle yatakları gerektiğinden büyük tasarlamaya çalıșırlar. Fakat yataklar yeterli emniyetli çalışma yükünü karşılayacak şekilde yapılmalıdır. Bazen yatağın boyutu başlangıç yükünü desteklemesi gerektiği zorunlu olarak kabul edilmiştir. Özel dizayn gereksinimleri ve sınırlamalarında örneğin uzay sınırlaması gibi başlangıçtaki yatak boyutlarını yeniden gözden geçirmek gerekebilir. Ön sınırlamalı yatak dizaynının performansında sonraki analizler için yatak boyutlarını yeniden gözden geçirmek (modifiye etmek ) gerekebilir.

\section{Gerekli Yatak Boyutu}

Gerekli yatak boyutu ya başlangıç gereksinimlerini ya da çalışma gereksinimlerinin karşılayacak şekilde olmalidir.

\section{Çalışma Durumu ve Sabit Yük}

Sabit yük $p_{\text {mean }}$ bir yatağın çalışmasında en önemli parametredir. Kaymalı yatakların bazen (yaklaşık 7 $M N / m^{2}$ ) gibi çok yüksek sabit yüklerde çalışması muhtemeldir. Bu durumda tasarımcı çok dikkatli olmalıdır. Tasarımcı mil ve yatak yüzeyleri arasında yeterli yağ film kalınlığı olup olmadığını teyit etmek ve yüksek yatak sıcaklıklarından kaçınmak zorundadır. Pratikte çoğunlukla yataklara uygulanan yükler doğru olarak bilinmez. Yatakta yük emniyeti sağlanamazsa yataklama kabiliyeti bozulabilir. Bunun sonucu olarak da yatak aşınabilir. Beyaz maden yataklar için sabit yük, yaklaşık $4 M N / m^{2}$ dan daha fazla olmamalıdır. Çoğu uygulamalarda yeterli bir film kalınlığı oluşabilmesi için sabit yük bu değerden daha az olmak zorundadır. Bundan dolayı müsaade edilen sabit yük Şekil 5.1 de görüldüğü gibi yağlayıcının viskozitesine bağlı olduğu kadar dN'in değerine de bağlıdır. Bu şekilde gerekli yatak genişliği b, mineral yağ kullanıldığında tasarımın başında tahmin etmede kullanılabilir. Su gibi düşük viskoziteli yağlayıcılar kullanıldığında müsaade edilen sabit yük Şekil 5.1 de kabul edilenden oldukça az olacaktır.

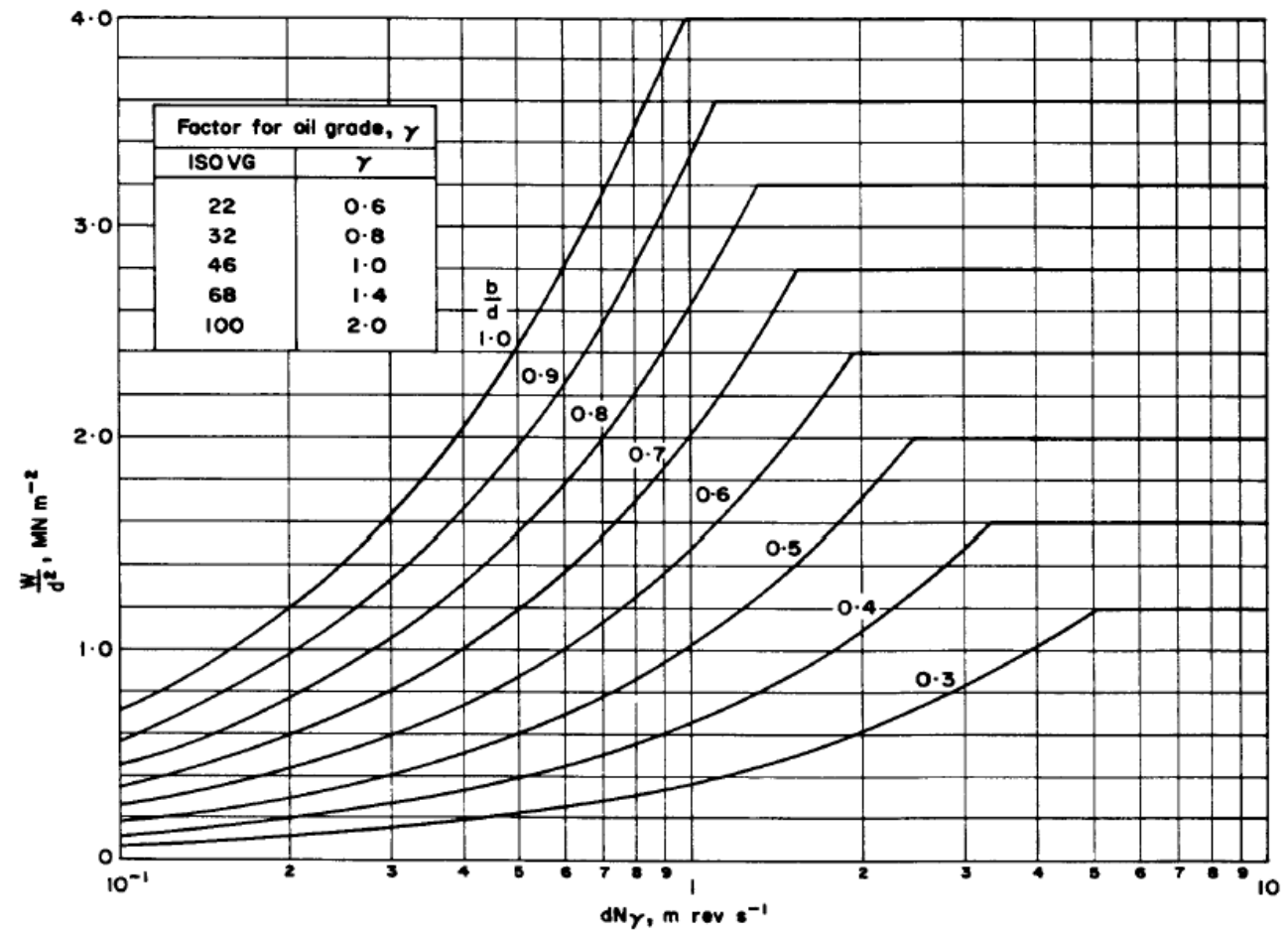

Şekil 6. Grafik için b/d oranı gereklidir 


\section{Harekete Başlangıç (Start-up) Gereksinimleri}

Yağlayıcı film harekete başlangıçta mil ve yatak yüzeylerini birbirinden ayıracak kadar gelişmemiştir. Genel olarak beyaz maden yatakların sık olan kalkma ve durma (birkaç günde bir) gerekli boyutu belirlemek için başlangıç sabit yük değeri 1.3 $\mathrm{MN} / \mathrm{m}^{2}$ alınabilir. Sık olmayan (bir gün veya daha az) start-stop (harekete geçme) durumlarında tahmin edilen başlangıç yükü olarak $2.5 \mathrm{MN} / \mathrm{m}^{2}$ alınabilir.

$$
b=\frac{W}{d p_{\text {mean }}}
$$

\section{Ön Sınırlamalı Yatak Boyutları}

Yatak uzunluğunun tahmin edilen değeri b, hem çalışma durumunu hem de start-up (ilk harekete geçiş) durumunu karşılayacak şekilde seçilmelidir. Tavsiye edilen b/d oranı 1'den daha az olmalıdır. Bu oranın (b/d) büyük olması halinde kenar oturması, mil ve yatak eksenlerinin paralel olmaması problemi ortaya çıkar. Bu değerler tasarımcılar tarafından hesaplanmıştır. Böyle bir problemle karşılaşıldığında mil çapının artırılması tavsiye olunur ve yatak geometrisi yeniden hesaplanmalıdır.

\section{Diğer Yatak Boyutları}

\section{Yatak Boşluğu}

Yatağın emniyetli bir şekilde çalışabilmesi için yatak boşluğu önemlidir. Yatak boşluğu oranının $c_{d} / c$ hem küçük hem de büyük değerleri önemlidir. $c_{d} / c$ nin küçük değerleri yatak sıcaklığının artmasına neden olurken, Şekil 7'de görüldüğü gibi büyük $c_{d} / c$ oranı ise ortalama yağlayıcı akış oranının azalmasına neden olur.

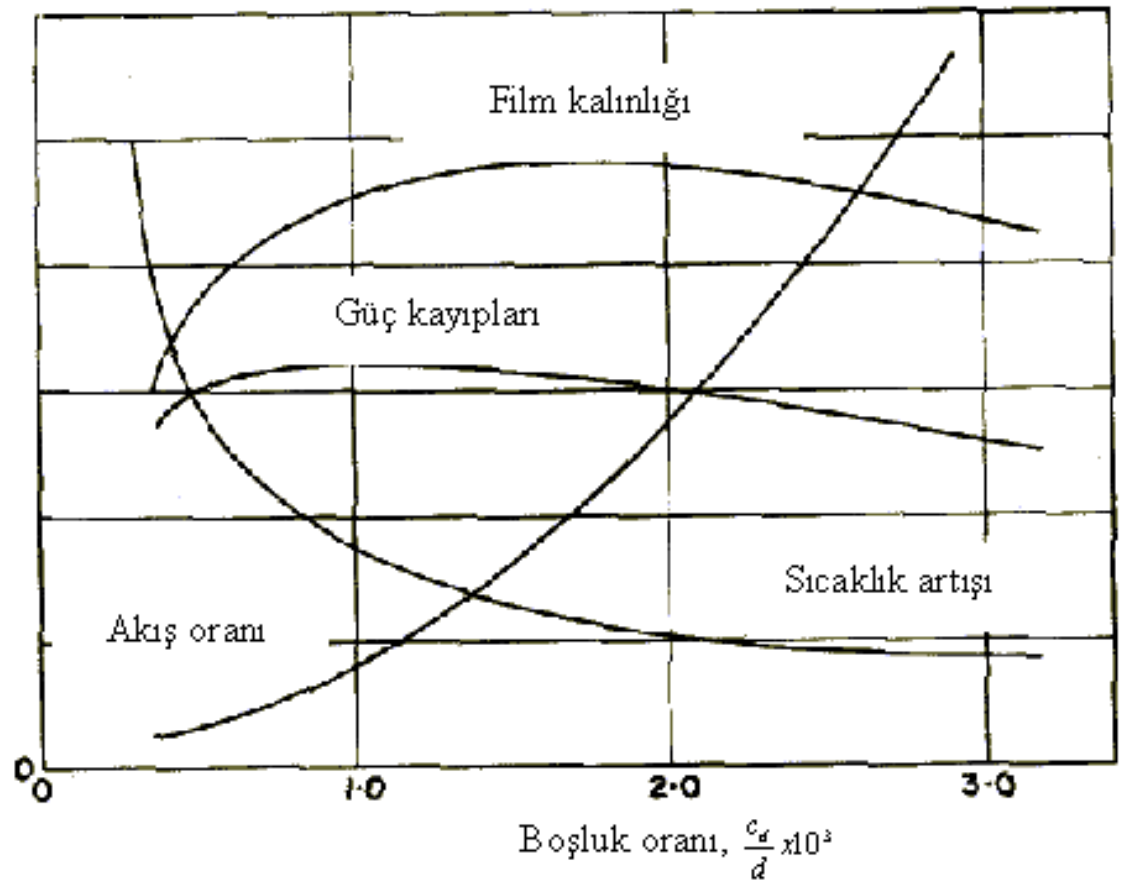

Şekil 7. Karakteristik film kalınlığının değişim miktarı, güç kayıpları, akış oranı, sıcaklık yükselişinin boşluk oranına göre değişimi

Şekil 7'de deneysel olarak belirlenen boşluk oranlarının çalışma şartları için uygunluğu verilmiştir. Çapsal boşluk imalat esnasındaki toleransa yakın olmalıdır. 


\section{Kanal (yiv) Boyutları}

Radyal kaymalı yataklarda yağ desteği çoğu uygulamalarda yatak genişliğinin $0.8(\mathrm{a} / \mathrm{b}=0.8)$ ve çevresel genişlikte $0.25 \mathrm{~d}$ olacak şekilde yağlayıcı kanallarıyla sağlanmaktadır. Kanal genişliğinin giriş akışını sinırlamaması amacı ile $20 c_{d}$ den daha az olmaması tavsiye edilir.

\section{PERFORMANS ANALIZZLERI}

$\mathrm{Bu}$ kısımda var olan dizayn yada yeni dizaynın performans analizi üzerine bilgiler verilecektir. Bir hidrodinamik kaymalı yatağın performansı yatağın boyutlarına, yüke, yağlayıcının efektif viskozitesine, mil ve yatak eksenlerinin çakışıp çakışmamasına bağlıdır. Hesaplama metotları ve yataklar için müsaade edilen fillm kalınlığı, güç kayıpları, yağlayıcı akış oranları ve yatak sıcaklıkları belirlenecektir. Performans yeterli olmadığı zaman tasarımcı yatağın boyutlarını sınır durumundaki verileri yeniden gözden geçirmelidir. Bir yatak dizayn edildiğinde ilk gerekenler yatağın yeterli minimum film kalınlığı ve kabul edilebilir bir maksimum sıcaklıkta çalışması tavsiye edilir. Dizaynın amacına ulaşması için kabul edilebilir performansı sağlanabilmesi için yatak parametreleri kolayca değiştirilebilir olması gerekmektedir. Bununla birlikte tasarımcılar için mevcut değer aralıkları pratiklik sağlar.

\section{Efektif Viskozite}

Bu kısımda performans tahmin metodu için gerekli olan değerler, yatağın yüklü kısmında yağlayıcının efektif dinamik viskozitesi $\eta_{e}$ ve yă̆ besleme kanallarındaki yağlayıcının dinamik viskozitesidir $\eta_{g}$. Bu viskoziteler $T_{e}$ ve $T_{g}$ yağlayıcı sıcaklıkları tarafından sınırlandırılmıştır. Bu yağlayıcı sıcaklıkları başlangıçta kabul edilir ve sonra bir iterative işlem kullanılarak hassaslaştırılır.

Filmde yağlayıcının efektif sıcaklığı $T_{e}$ daima yatak besleme sıcaklığı $T_{f}$ den yüksek olacaktır. Genellikle düşük hızlarda $T_{f} 10 \mathrm{~K}$ ve yüksek hızlarda $30 \mathrm{~K}$ sınırını aşmamalıdır. Başlangıçta $T_{g}=T_{e}$ alınabilir. Tasarımcı yatağın performansını analiz ederken yağlayıcıya ait sıcaklık-viskozite eğrisine sahip olmalıdır. Dinamik viskoziteler $\eta_{e}$ ve $\eta_{g}$ uygun yağlayıcı sıcaklıkları $T_{e}$ ve $T_{g}$ sonra belirlenmelidir. Şekil 2' de yaygın olarak kullanılan mineral yağlar için sıcaklık-viskozite karakteristikleri görülmektedir.

\section{Eksantrisite Oranı}

Eksantrisite oranı $\varepsilon$ bir hidrodinamik kaymalı yatağın analizinde temel parametredir. Değeri mil ve yatak eksenleri aynı doğrultuda olan yataklar için boyutsuz yük hesaplandıktan $W^{\prime}$ sonra Şekil 3'den bulunabilir.

\section{Güç Kayıpları}

Güç kayıpları genel tasarımla ilgilidir fakat yatak sıcaklıklarının hesaplanması için de gereklidir. Yatağın güç kayıpları bazı uygulamalarda kritik olabilir. Şekil 4'den seçilen b/d değerleri için güç kayıpları bulunabilir.

\section{Yağlayıcı Akış Oranları}

Yağlayıcı akış oranları ısıl dengeyi kurmak ve gerekli yağ beslemesini tahmin etmek içindir. Yatak akış oranı $Q$ şöyle verilmektedir.

$$
Q=Q_{p}+\frac{a}{b} Q_{s}
$$

Kanalların açısal uzunluğu 40 dereceyi aşmamalıdır. $Q_{p}$ besleme akış oranı şöyle hesaplanabilir. 


$$
Q_{p}^{\prime}=\frac{Q_{p} \eta_{g}}{c_{d}^{3} p_{f}}=0.026\left[\frac{\left(1-0.2 \frac{a}{b}\right)}{\left(\frac{b}{a}-1\right)^{0.333}}+\frac{0.007 \Delta \theta}{\left(1-\frac{a}{b}\right)\left(\frac{b}{d}\right)}\right] F
$$

Burada kanal fonksiyonu $F$, Şekil 5'den bulunabilir. $\frac{a}{b}=0.8$ olduğunda $Q_{p}$ daha basit olarak aşağıdaki ifade ile hesaplanır.

$$
Q_{p}^{\prime}=\frac{Q_{p} \eta_{g}}{c_{d}^{3} p_{f}}=0.035\left(1+0.026 \frac{\Delta \theta}{b / d}\right) F
$$

veya $\Delta \theta=30^{0}$ için

$$
Q_{p}^{\prime}=0.035\left(1+\frac{0.078}{b / d}\right) F
$$

Boyutsuz idealleştirilmiş yan akış oranı $Q_{s}^{\prime}$ Şekil 6 kullanılarak bulunabilir. Boyutsuz sistemde tekrar sirküle eden yağ akışı $Q_{r}^{\prime}$ bu değer yatak sıcaklıkları hesaplanırken gereklidir ve $Q_{r}^{\prime}$ aşağıdaki ifadeden bulunabilir.

$$
Q_{r}^{\prime}=\frac{Q_{r}}{c_{d} N d b}=0.8(1-\varepsilon)
$$

\section{Yatak İçerisindeki Sıcaklıklar}

Yatağın maksimum sıcaklı̆̆ı emniyetli çalışmayı sağlayabilmek için gereklidir. Çıkış sıcaklığından yağlayıcının bozulup bozulmadığı kontrol edilebilir. Efektif film sıcaklığı $T_{e}$, kanal sıcaklığı $T_{g}$ ve maksimum yatak sıcaklığı $T_{\max }(6)$, (7) ve (8) eşitliklerinden yağlayıcı akış oranları ve güç kayıplarının tahmin edilen değerleriyle birlikte elde edilir.

$$
\begin{aligned}
& Q \geq Q_{s} \text { için } \quad T_{e}-T_{f}=\left(\frac{K H}{\rho C Q}\right)\left(\frac{\phi Q_{r}+Q}{\phi Q_{r}+K_{s} Q_{s}}\right) \\
& Q<Q_{s} \text { için } \quad T_{e}-T_{f}=\left(\frac{K H}{\rho C Q}\right)\left(\frac{\phi Q_{r}+Q}{\phi Q_{r}+K_{s} Q}\right) \\
& T_{g}-T_{f}=\left(\frac{\phi Q_{r}}{\phi Q_{r}+Q}\right)\left(T_{e}-T_{f}\right) \\
& \text { ve } \quad T_{\max }-T_{g}=\phi\left(T_{e}-T_{g}\right)
\end{aligned}
$$

Faktörler aşağıdaki eşitliklerle verilmiştir.

$$
\begin{aligned}
& \phi=1+2.75 \varepsilon^{0.5} \frac{P_{e}}{P_{e}+10 Z} \quad 1<P_{e}<250 \\
& K=\frac{P_{e}}{P_{e}+Z} \text { ve } K_{s}=\frac{5-\phi}{4}
\end{aligned}
$$


Burada Peclet sayıs $P_{e}=\frac{N c_{d}^{2}}{\kappa}$ ve $Z=\frac{6}{2-\varepsilon}$

Mineral yağlar için yaygın olarak $\rho C=1.7 .10^{6} \mathrm{~J} / \mathrm{m}^{3} \mathrm{~K}$ ve $\kappa=0.08 .10^{-6} \mathrm{~m}^{2} / \mathrm{s}$

Efektif film sıcaklığı $T_{e}$ ve kanal sıcaklığı $T_{g}$ için bir değere sahip olunduğunda bu değerler başlangıçta kabul edilen değerlerle karşılaştırılmalıdır. Hesaplanan değerler arasında anlamlı bir fark olduğu zaman hesaplanan ve eski değerlerin aritmetik ortalamasına eşit yeni $T_{e}$ ve $T_{g}$ değerleriyle hesap tekrarlanmalıdır. Bu iterasyona $T_{e}$ ve $T_{g}$ deki değişim $2 \mathrm{~K}$ den az olana kadar devam edilmesi tavsiye edilir. Yatak vasıtasıyla yağlayıcı sıcaklığındaki yükselme $\left(T_{\text {out }}-T_{f}\right)$ aşağıdaki eşitliğe göre yağlayıcı akış oranı ile ilgilidir.

$$
T_{\text {out }}-T_{f}=\frac{K H}{\rho C Q}
$$

Alternatif bir yol olarak hesaplanan ve eski değerlerin aritmetik ortalamasına eşit $T_{e}$ nin yeni değeri olacak fakat eşitlik 6.7 de kabul edilen $T_{g}$ nin yeni değerine dayanarak yani;

$$
\left(T_{g}-T_{f}\right)_{k a b u l}=\frac{T_{g}-T_{f}}{T_{e}-T_{f}}\left(T_{e}-T_{f}\right)_{k a b u l}
$$

\section{Film Kalınlıkları}

Minimum film kalınlığının değeri yatağın kontrol edilebilir emniyetli çalışma şartları için gereklidir. Genelde, belirli bir çalışma durumunda yatağın boyutları arttırıldığında film kalınlığı da artar. Bununla birlikte geniş yataklar, kısa yataklardan daha büyük güç kaybına sahip olacaklardır. Mil ekseni ile yatak ekseni aynı doğrultuda olan bir yatak için minimum film kalınlığı şöyle verilmektedir.

$$
h=(1-\varepsilon) \frac{c_{2}}{2}
$$

Pratikte bazen mil ekseni ile yatak ekseni aynı doğrultuda olmayabilir bu bölümdeki kabuller bu durumun dışındadır. Eksenlerin aynı doğrultuda olmaması birkaç faktörden dolayı olabilir. Bunlardan bir tanesi yük altında milin eğilmesi nedeniyledir [2]. Paralel olmama nedeniyle minimum film kalınlığı yatağın kenarında ve değeri $h$ nın değerinden daha az olacaktır. Tüm durumlarda özellikle büyük bir eksen paralelliğinin olmadığı durumda film kalınlığının değeri azalır ve bu durumlarda $h_{\text {edge }}$ film kalınlığı Şekil 8 kullanılarak tahmin edilebilir. $h_{\text {edge }}$ nin hesaplanan değeri minimum film kalınlı̆̆ kriteriyle karşılaştırılmalıdır. Hesaplanan değer yatak dizaynı için yeterli olmadığı zaman film kalınlığını artırmak için değişiklik yapmak zorunlu olacaktır. Bu yatak boyutlarında bir miktar artı̧̧la veya viskozitesi yüksek bir yağ kullanmakla üstesinden gelinebilinir.

\section{LIMIT KRITERLERI}

Bir kaymalı yatağı yeterli bir film kalınlığında emniyetli olarak çalışırabilmek için mil ve yatak yüzeyleri arasında yatağın ve yağlayıcının sıcaklığının sınırlanan limit değerlerinin muhafaza edilmesi gerekmektedir. Tasarımcı bu yüzden her zaman dizaynında ve kontrollerinde minimum film kalınlığı ve maksimum sıcaklık kriterlerini doğrulayacak değerde olmalıdır. Güvenirlik en üstün öneme sahip olduğunda maksimum sıcaklık ve minimum film kalınlığı limitlerinde çalışmama tavsiye edilir.

\section{Minimum Film Kalınlığı}

Emniyetli müsaade edilebilir film kalınlığı $h_{s}$, Şekil 8'de gösterildiği gibi yatağın boyutlarına bağlıdır. Yağlayıcı içerisinde kirletici (toz, pislik, toprak vs. gibi ) parçacıkların bulunması yatak yüzeyinin bozulmasına 
neden olabilir. Ayrıca yağ filtrasyonunun iyi olmaması yağ içerisinde yabancı parçacıkların artmasına neden olabilir. Yatağın yüzey pürüzlülüğü ve beklenen (umulan) film kalınlığı arasında bir bağ (uyum) olması tavsiye edilir ve bu yüzden dar yatakların, geniş yataklardan daha yüksek standartlarda yüzeyinin işlenmesi tavsiye olunur. Yatak yüzey pürüzlülüğünün herhangi bir aynı hizada olmama durumu dikkate alınmaksızın minimum film kalınlığının 1/20 den daha az olmaması tavsiye edilir.

$$
R_{a}<\frac{1}{20}
$$

\section{Maksimum Sıcaklık Kriteri}

Yatak malzemesinin akma mukavemeti sıcaklığa bağlıdır. Bazı çalışma şartları altında yatak sıcaklığı yükseliyorken, yatak malzemesinde plastik deformasyon meydana gelir. Bunu hesaba katmak için yatağı her zamanki $T_{\max }$, maksimum yatak sıcaklığında tutmak gerekir. Maksimum müsaade edilebilir yatak sıcaklığı kullanılan malzemenin kalınlığına bağlıdır. Beyaz metalde genellikle maksimum yatak sıcaklığı $120{ }^{0} \mathrm{C}$ dir. Fakat yatağın normal çalışma esnasında bu sıcaklığa ulaşmayacak şekilde dizaynının yapılmış olması gereklidir. Eğer yüksek sıcaklıklarda çalışılacaksa bir alüminyum kalay veya bakır-kurşun alaşımlı yataklar düşünülmesi gerekmektedir. Alüminyum-Kalay, bileşeninin \%40’ı kalaydır. 150-160 ${ }^{0} \mathrm{C}$ sıcaklıklarda kullanılabilir. Alaşımım gömme kabiliyeti (yağ içerisindeki kirli bileşenleri absorbe etme kabiliyeti) ve boyutsal değişimlere dayanıklılığı hemen hemen beyaz madene eşittir. Bakır-Kurşun alaşımlı yataklar $200{ }^{0} C$ ve daha yüksek sıcaklıklarda kullanabilir. İyi bir yağ filitrasyonu gerekmektedir [3]. Genelde bronzlar yüksek yatak sıcaklıklarında kullanılabilir fakat bronzların harekete ilk başlama (start-up) rodaj özelliği çak kötüdür. Bu yüzden normal çalışma şartları boyunca limit yatağın sıcaklığa gelmesini tasarımcılar müsaade etmezler. Yataktan ayrılan yağlayıcının sıcaklığı oksidasyon nedeniyle bozulmadan kaçınılacak şekilde sınırlandırılmalıdır. Atmosferle temasta hidrokarbon yağlar için tavsiye edilen limit sıcaklığı normal yağlayıcı ömrü için $80{ }^{\circ} \mathrm{C}$ dir. Çıkış sıcaklığı $T_{\text {out }}$, en kolay şekilde ölçülen sıcaklık olması sebebiyle hesaplamalarda, yatak performansını kontrol etmede bu sıcaklık kullanılır. Bununla birlikte yatağın performansı hakkında karar vermek için bu sıcaklık yeterli değildir fakat uzun bir dönem izleme parametresi olarak kullanılabilir. Örneğin, çıkış sıcaklığı aylarca $70{ }^{0} \mathrm{C}$ de sabit olmuşken birden $80{ }^{0} \mathrm{C}$ yükselmesi tavsiye olunmaz.

\section{DİĞER DİZAYN FAKTÖRLERİ}

\section{Yağlayıcı Desteği}

Hidrodinamik kaymalı yataklar için uygun yağlayıcı yük taşıyıcı filmi yeterli miktarda yağ boşluğu vasıtasıyla yağlayıcının sürekli bir akışına izin vermeli ve kabul edilebilir bir limit içerisinde sıcaklık yükselişine müsaade etmelidir. Yağlama sisteminin hem hesaplanan akış oranı $Q$, hem de kabul edilen besleme basıncı $p_{f}$ yi besleyecek kapasitede olması tavsiye edilir. Sistem bunu sağlamıyorsa ya oran artırılmalı ya da yatak dizaynı yağlayıcı akış gereksinimlerini azaltacak şekilde daha iyi hale getirilmelidir. Yağlayıcının bazı uygulamalarda ağırlığı önemli olabilir.

\section{Alternatif Besleme Şekilleri}

İki alternatif eksenel kanallı besleme düzeni bu çalışmada incelenmiştir. Ayrıca yatağa çevresel kanal ve yatağın yüksüz kısmına tek bir delik delinerek de yağ beslemesi sağlanabilir. Eğer yük doğrultusu değişkense en iyi yağlayıcı besleme şekli [4] genelde merkezde çevresel kanalla sağlanır. Yatak kanalla ikiye bölünmüştür. Ve iki ayrı yatakla yataklanmış gibi analiz edilmek zorundadır.

Yatağın yüksüz yarı kısmı üzerine bir delikle besleme dar yataklar için tatmin edici olabilir. Nispeten yüksek besleme basıncı gereken çoğu durumlarda yeterli bir yağlayıcı akış oranını sağlamak için gerekli olabilir.

\section{Mil Pozisyonu}

Mil merkezinin geomerik yeri önemlidir. Mil merkezinin yeri eksantrisite oranı $\varepsilon$ ve konum açısı $\psi$ 
nın bilinmesiyle belirlenebilir. Eksantrisite oranı milin radyal boşluk içerisinde izafi hareket miktarını gösterir. Eksantrisite oranı yatağın analizi esnasında tesbit edilmektedir. $\varepsilon=0$ ise mil yatağın merkezindedir ve $\varepsilon=1$ olduğunda mil yatak yüzeyine temas etmektedir. Şekil 9'dan ise konum açısı tespit edilebilir.

\section{Laminer Olmayan (Türbülans) Durumlar}

Bu çalışmada ele alınan dizayn ve analiz metodları yanlızca yatağın laminer akışlarda çalışması için uygulanabilir. Yatak uygulamalarında genelde bu durum normaldir. Bununla birlikte yüksek hızlarda, yağlayıcının viskozitesinin düşük olduğu (örneğin su gibi ) uygulamalarda ve büyük boşluklarda yağ akışları laminer olmayabilir. Laminerden türbülansa (laminer olmayana) geçiş sınırı Şekil 8'de verilmiştir. Laminer olmayan akışta yatağın çalışması durumunda yatağın dizayn ve analizleri [5]'de verilmiştir.

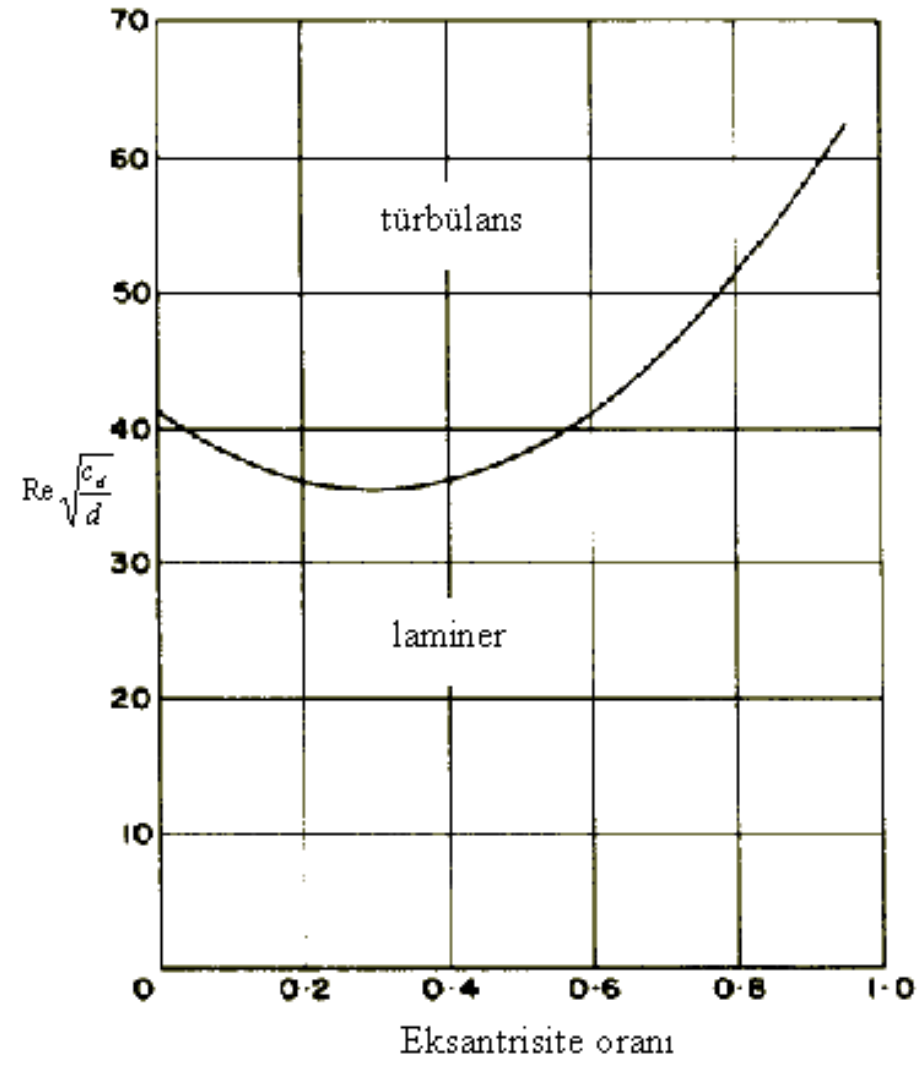

\section{Sonuç}

Şekil 8. Türbülanslı akışa geçiş sınırı

Bu çalışmada, eksenel kanallı yağlanmış hidrodinamik kaymalı yataklar için gerekli hesaplama metodu verilmiştir. Burada sunulan metotla, mevcut yatakların bozulma analizleri de yapılabilir, yatağın performansı araştırılabilir ve yatağın performansını yükseltmek için yapılabilecekleri araştırmak için de kullanılabilir. Burada sunulan metot yük doğrultusunun sağında ve solunda iki eksenel kanallı yatak için kullanılabilir. Alternatif yağ dağıtım şekilleri de müzakere edilebilir.

\section{KAYNAKLAR}

1. Calculation methods for steadily loaded axial groove hydrodynamic journal bearings. Low viscosity process fluid lubrication (To be used in conjuction with Items No. 84031 and 85028) Item No 86008, ESDU International, London, July 1986.

2. The deflections and slopes of shafts or beams of constant or stepped section. Item No. 69017, ESDU International, London, June 1969. 
3. Selection of filter rating for lubrication systems. Item No.83030, ESDU International, London, November 1983.

4. Calculation methods for steadily loaded central circumferential groove hydrodynamic journal bearings. Item No.90027, ESDU International, London, November 1990.

5. Calculation methods for steadily loaded axial groove hydrodynamic journal bearings. Superlaminar operation. Item No. 85028, ESDU International, London, November 1985.

\section{SEMBOLLER VE BİRIMLERI}

$a \quad$ yağlayıcı kanalın eksenel uzunluğu

$b \quad$ yatağın eksenel uzunluğu

C yağlayıcıya ait ısı iletim katsayısı

$c_{d} \quad$ çalışma şartlarındaki radyal boşluk

d mil çapı

$e \quad$ mil ve yatak eksenleri aynı hizadaki bir yatak için eksantrisite

$F Q_{p}$ nin hesaplanması için gerekli kanal fonksiyonu

$g$ ağırlık nedeniyle ivmelenme

$H$ güç kayıpları

$H^{\prime}$ boyutsuz güç kaybı $[m]$

$[m]$

$[\mathrm{J} / \mathrm{kgK}]$

$[m]$

$[m]$

$[m]$

$\left[m / s n^{2}\right]$

$[W]$

$$
H^{\prime}=\left(\frac{H}{\eta_{e} N^{2} d^{2} b}\right)\left(\frac{c_{d}}{d}\right)
$$

$h \quad$ mil ve yatak eksenleri aynı hizadaki bir yatak için ele alınan en küçük film kalınlığı $[m]$

$h_{\text {edge }}$ mil ve yatak eksenleri aynı hizada olmayan bir yatak için ele alınan en küçük filım kalınlığı

$h_{s} \quad$ müsaade edilebilir emniyetli film kalınlığı

$[m]$

$K$ güç kaybı faktörü

$K_{s}$ sıcaklık artışının hesabı için ampirik faktör

$M \quad$ yatakla ilgili olan rotor kütlesi

$N \quad$ milin dönme frekansı (devir sayısı)

$P_{e} \quad$ sıcaklık artışının hesabı için gerekli olan Peclet Sayısı

$[\mathrm{rev} / \mathrm{s}]$

$p_{f} \quad$ yağın beslenme basıncı

$P_{e}=\frac{N c_{d}^{2}}{\kappa}$

$p_{\text {mean }}$ belirli yük $\quad p_{\text {mean }}=\frac{W}{b d}$

$\left[N / m^{2}\right]$

$Q \quad$ yatak içerisindeki yağın akış oranı

$Q_{p} \quad$ kanallardaki yağın besleme basıncı yağın akış oranı

$\left[N / m^{2}\right]$

$Q_{p}^{\prime} \quad$ kanallardaki yağın boyutsuz besleme basıncı yağın akış oranı

$\left[m^{3} / s\right]$
$\left[m^{3} / s\right]$

$Q_{r} \quad$ sistemde dolaşan yağın akış oranı

$Q_{p}^{\prime}=\frac{Q_{p} \eta_{g}}{c_{d}^{3} p_{f}}$

$Q_{r}^{\prime} \quad$ sistemde dolaşan boyutsuz yağ akış oranı

$\left[m^{3} / s\right]$

$Q_{r} \quad$ sistemde dolaşan boyutsuz yağ akış oranı

$Q_{r}^{\prime}=\frac{Q_{s}}{c_{d} N b d}$

$Q_{s} \quad$ idealleşmiş yan akış oranı

$\left[m^{3} / s\right]$ 
$Q_{s}^{\prime} \quad$ idealleşmiş boyutsuz yan akış oranı

$R a \quad$ yüzey pürüzlülüğü değeri

Re yatakta Reynolds sayıs1

$T_{e} \quad$ yatağın yüklü kısmındaki yağın efektif sıcaklığı

$T_{f} \quad$ beslenen yağın sıcaklığ

$T_{g} \quad$ kanallardaki yağın sıcaklığı

$T_{\max } \quad$ maksimum yatak yüzey sicaklı̆̆ı

$T_{\text {out }} \quad$ yataktan çıkan yağın sıcaklığı

$W \quad$ yük boyutsuz yük $W^{\prime}=\left(\frac{W}{\eta_{e} N b d}\right)\left(\frac{c_{d}}{d}\right)^{2}$

w çevresel doğrultuda ölçülen kanalın genişliği

$Z \quad$ sıcaklık artışının hesabında kullanılan faktör

$\beta \quad$ mil ve yatak eksenlerinin aynı hizada olmaması kaçıklık

$\gamma \quad$ yağın cinsine göre bir faktör

$\delta \quad$ yatak genişliği boyunca mil ve yatak eksenlerinin aynı hizada olmaması

$\Delta \theta \quad$ yağ kanalının açısal uzunluğu

$\varepsilon \quad$ mil ve yatak eksenlerinin aynı hizada bir yatak için eksantrisite oranı

$\eta_{e} \quad$ yatakta yüklü kısımdaki yağlayıcının efektif dinamik viskozitesi

$\eta_{f} \quad$ yatakta kanallardaki yağlayıcının dinamik viskozitesi

$\kappa \quad$ yağlayıcının 1 sıl geçirgenliği

$\rho \quad$ yağlayıcının yoğunluğu

$\Phi \quad$ sıcaklık artışının hesabında kullanılan ampirik faktör

$\psi \quad$ konum açısı (merkezler doğrusu ve yük doğrusu arasındaki
$Q_{s}^{\prime}=\frac{Q_{s}}{c_{d} N b d}$

$[m]$

$\operatorname{Re}=\frac{\pi d N c_{d} \rho}{2 \eta_{e}}$

$\left[C^{o}\right]$

$\left[C^{o}\right]$

$\left[C^{o}\right]$

$\left[C^{o}\right]$

$\left[C^{o}\right]$

[N]

[m]

[m]

[derece]

$\varepsilon=2 e / c_{d}$

$\left[N s / m^{2}\right]$

$\left[N s / m^{2}\right]$

$\left[\mathrm{m}^{2} / \mathrm{s}\right]$

$\left[\mathrm{kg} / \mathrm{m}^{3}\right]$ 